\title{
Developing and Delivering a Remote Experiment based on the Experiential Learning framework during COVID-19 Pandemic
}

\author{
W.D. Kularatne ${ }^{1}$, Lasanthika H. Dissawa ${ }^{2 *}$ ๑htps://orcid.org/0000-0002-0246-6555, T.M.S.S.K. Ekanayake3, \\ Janaka B. Ekanayake 4 \\ 1,2,4 Department of Electrical and Electronic Engineering, Faculty of Engineering, University of \\ Peradeniya, Sri Lanka. \\ ${ }^{3}$ Department of Education, Faculty of Arts, University of Peradeniya, Sri Lanka. \\ *e-mail: ${ }^{1}$ kule@ee.pdn.ac.lk, ${ }^{2 *}$ lasanthikadissawa@yahoo.com, ${ }^{3}$ syatigammana@yahoo.com, \\ ekanayakej@eng.pdn.ac.lk
}

\begin{tabular}{l}
\hline \multicolumn{1}{c}{ Article Information } \\
\hline Received: December 12, 2021 \\
Revised: January 25, 2022 \\
Accepted: January 30, 2022 \\
Online: March 03, 2022
\end{tabular}

Keywords learning, learning technology, remote laboratory

\begin{abstract}
The students following Engineering disciplines should acquire a conceptual understanding of the concepts and the processors and attitudes. There are two recognizable learning environments for students: classroom and laboratory environments. With the COVID-19 Pandemic, both environments merged to online environments, impacting students' processes and characteristic attitudes development. This paper introduces a theoretical framework based on experiential learning to plan and deliver processes online. A case study based on the power-factor correction experiment was presented. The traditional experiment that runs for 2 hours was broken into smaller tasks such as pre-lab activity, simulation exercise, PowerPoint presentation, remote laboratory activity, and final report based on the experiential learning approach. The delivery of the lab under online mode delivery was presented. Then students' performance was compared before and after the online mode of delivery. It was found that students' performance on average has a distinct improvement. In order to obtain students' reflections about the online experiential learning approach, a questionnaire that carries close and open-ended questions was administered. The majority of the students liked the approach followed and praised for allowing them to experiment in a novel way during the COVID-19.
\end{abstract}

\section{INTRODUCTION}

Teaching engineering means more than enabling students to acquire knowledge. It is necessary to foster comprehension of a combination of content, processes, and characteristic attitudes related to the topic being studied. Content includes abstract concepts, laws, and theories, whereas processes include observation, classification, measurement, inference, prediction, and communication. Characteristic attitudes involve being curious, imaginative, and enthusiastic about asking questions and solving problems. It is important to focus on developing these three dimensions among students.

In Engineering disciplines, the content is transferred to students in a classroom environment. The only way to grasp the practical knowledge and experiences for processes is through laboratory 
experiments. Especially, the experience obtained through experimental work is important as students are focused more on solving problems in real situations. Further, the practical experience gained through laboratory experiments helps to improve skills of applying theoretical knowledge in practical situations (L. Feisel et al., 2002).

The COVID 19 pandemic has imposed a global shutdown of various activities, including educational activities. It resulted in transforming the classroom learning environment into an online learning environment. The challenges and the opportunities of crisis-response migration methods of universities are discussed in (Adedoyin \& Soykan, 2020). With COVID 19 pandemic, the content delivery is done online successfully using platforms like Zoom and Microsoft Teams. Reference (Tang et al., 2020) shows that flipped learning improved students' learning, attention, and evaluation of courses. However, engineering educators always question whether they can develop processes and characteristic attitudes of students when switched to an online learning environment.

Reference (Almeida et al., 2009) state that to provide a good context for making students effectively understand what they are being taught, tasks are designed as investigation activities and use real data and asking for problem-solving, that is, learning by experience, can effectively be used. In experiential learning, the 'learning' relies on the practical aspects and the experience being considered the key to success in the educational activity. This approach based on experience adds good value to the student's individuality develops his/her acting skills, reflection skills, critical and innovative thinking, initiative, motivation, curiosity, and trust in his/her person (Gorghiu \& Santi, 2016). According to (Kolb 1984), experiential learning consists of four stages: concrete experience, reflective observation, abstract conceptualization, and active experimentation. Learning starts with the active involvement in getting experience by doing something individually or as a team; then, the learner takes a time-out from 'doing' and stepping back from the activity and reviewing what has been experienced and done. The above stages are followed by making sense of what has happened. They involve interpreting the events and understanding the relationships between them, drawing upon theory from textbooks for framing and explaining events, models they are familiar with, ideas from colleagues, previous observations, or any other knowledge they have developed. Finally, the learner considers how they will put what they have learned into practice. This cycle is shown in Figure 1. An improved form of Kolb's experiential learning cycle consists of contextually rich concrete experience, critical reflective observation, contextualspecific abstract conceptualization, and pragmatic active experimentation is proposed in (Morris, 2020).

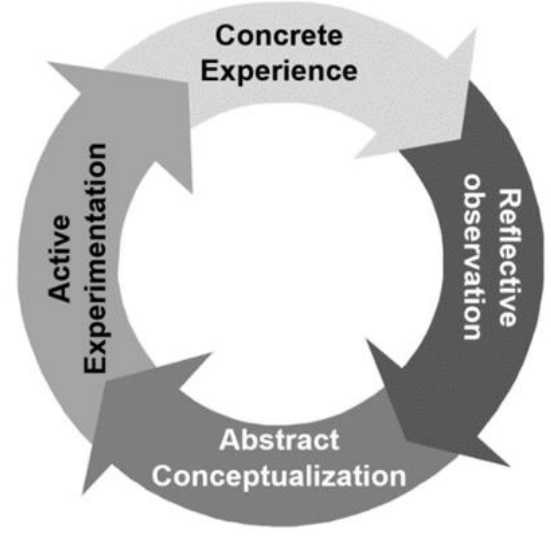

Figure 1. Experiential learning cycle

\section{Online Modes of Getting Concrete Experience}

Before the Pandemic, most of the experiments were performed in the laboratory and simulation environments. In the laboratory environment, the students work on real equipment and instruments, and they obtain the skills to use measuring equipment and experiences of real-world practice problems. On the other hand, the simulation laboratories are conducted as a pre-lab exercise to obtain an idea of the actual outcome of the experiment (L. D. Feisel \& Rosa, 2005) before performing it in a real laboratory. Also, they are conducted for explaining theoretical concepts (Balamuralithara \& Woods, 2009). Further, simulation laboratories are conducted as an alternative way of doing experiments related to expensive

IJAE Page 2 
or large systems, which are not practical in a university laboratory environment. Simulations are also used to demonstrate the events that are not easily seen, such as current flow, heat transfer, and electromagnetic fields (Bourne et al., 2005). However, as the software represents simplified mathematical models of real complex systems (Mosterman et al., 1996), in some cases, the simulation does not provide accurate results. Therefore, during the COVID-19 Pandemic lock-down period, many universities explored online modes of performing experiments such as (a) simulation labs, (b) remote labs, and (c) virtual labs (Odeh et al., 2013).

From simulation-based laboratories, the student's experience and practical knowledge depend on the software's capabilities, authenticity, and constraints (Ertugrul, n.d.). However, as mentioned earlier, it can be conducted as a substitution for some experiments. For example, reference (Das, 2018) proposes a MATLAB-Simulink modeling-based experiment to understand the characteristic of solar P.V. cells and solar P.V. systems. A virtual microgrid experiment introduced in (Chai et al., 2020) uses Simscape, an electrical power system toolbox in the M.A.T.L.A.B./Simulink software package, to model the microgrid. Students can download and install software packages and libraries on their personal computers and do the experiment remotely. The simulation tools give a robust platform to create models and help analyze the behavior and performance of systems but do not provide the students with a feeling of the real presence of laboratory equipment (Peterson \& Feisel, n.d.).

A laboratory that could give access to operate and control the real equipment via the internet is called a remote lab. It allows the students to undertake the experiments through the internet. Students can access the remote lab using their personal computers via a web browser application and send commands to control the lab equipment. The commands will go through a server and execute the command in the real equipment. The results of the experiment will be displayed on the student's computer. For example, a web API that conforms to the Web of Things standard to control a microscope was developed (Collins et al., 2021). It provides a modern graphical control interface and allows multiple microscopes to be controlled by one computer.

Further, it facilitates sharing of equipment between local or remote users. The steps of implementing remote microscopy are discussed in (Goldberg \& Dintzis, 2007). A digital camera attached to a light microscope provides the images of slides. The students can control this light microscope from a remote location via virtual microscopy software. The authors (Odeh et al., 2013) created a remote electronic Engineering lab based on Augmented Reality using a video camera and real experimental electronic tool kit. The camera transfers a live video of the electronic kit at the remote lab. In this remote lab, students can draw circuit connections on a webpage. Then, after the verification of the connections, the data were emulated onto a real multimeter. The remote lab provides experiences of practical issues that would not occur in a simulation environment (Ferreira et al., 2002). Therefore, remote labs are good choices for distance learning, and it allows the students to do experiments on real equipment located at a distance through the internet.

The virtual lab is not a real lab, but the entire infrastructure required for a real lab setup is obtained through computer-generated graphics, and it generates results from software simulations ( $\mathrm{Ma}$ \& Nickerson, 2006). Some virtual labs are developed only using computer-generated graphics, and some are developed using computer-generated graphics, virtual reality sensors, and leap motion control devices. In the latter, virtual reality sensors will capture the overall body movements and send the information to the computer to render them in the virtual environment. Further, the hand and finger movements are identified by the leap motion device, and it communicates with the virtual reality sensor and transfers this data to the computer to translate the students' movements into a virtual environment. The graphics in a virtual environment are maintained in the same form as a real device. This kind of virtual laboratory effectively increases students' knowledge, and understanding of handling equipment as students can visualize and experience the whole experimental process. Reference (Hasan et al., 2020) presented a virtual electric machines laboratory using Oculus Rift, Unity3D, and Leap Motion to do experiments in a safe environment to gain a broad understanding of the concepts of how electric machines work. In addition, a virtual instrumentation and measurement laboratory was reported (Valdez et al., 2014). Since it uses 3D components, students can get a real visualization of the circuit components. However, this is a full software program (no hardware components were included) that will not provide real results. A virtual lab for real-time control of a mobile robot is presented (Solak et al., 2020). An I.P. camera was fixed in this lab to monitor the indoor laboratory and the mobile robot in

IJAE Page 3 
real-time. The students can place a virtual target or virtual obstacles anywhere on the video generated by the I.P. camera. The navigation of the robot is monitored through the personal computer web server. The web server on the single-board computer in the robot can communicate with the student's P.C. It can execute the developed application software on the robot.

Further, the robot can control manually through the web environment. From this kind of simulation-based virtual lab, students do not gain experience in analyzing and interpreting real-world results. Even though the literature provides different online approaches that can be applied to develop skills and experience related to processors, they do not provide a theoretical framework that can be used when developing and delivering online experiments. The paper presents an experiential learning approach for a remote power factor correction experiment as a case study.

\section{METHODS}

According to (Osipov et al., 2015), the ideal online lesson duration is 15-20 min. It further states that it is hard for both the teacher and the student to study for more than 30 minutes. Further, reference (Basilaia \& Kvavadze, 2020), which reports a transition to the online mode of delivery during the COVID19 Pandemic, states that when the online teaching has started, changes in the duration of the online lessons were done to avoid prolonged contact of the students with a computer. Considering these facts, the typical laboratory session was changed while following the experiential learning cycle shown in Figure 1. This laboratory session was given to the students after a comprehensive lecture. In order to provide the laboratory session as short duration lessons, it was planned as described in Table 1. In addition, a PowerPoint presentation was used to reiterate the subject content after they had completed the first simulation exercise.

\section{Table 1. Activities based on the experiential learning cycle}

\begin{tabular}{lll}
\hline \multicolumn{1}{c}{ Experiential learning cycle } & \multicolumn{1}{c}{ Activity } & \multicolumn{1}{c}{ Description } \\
\hline Active experimentation & Pre-lab work & $\begin{array}{l}\text { It is a personalized activity and } \\
\text { discusses in more detail in Section } 1 .\end{array}$ \\
\hline $\begin{array}{l}\text { Concrete experience and } \\
\text { Reflective observation }\end{array}$ & $\begin{array}{l}\text { Simulation and } \\
\text { reflections }\end{array}$ & $\begin{array}{l}\text { A simulation followed by several short } \\
\text { questions was included for students to } \\
\text { reflect on the simulation activity. The } \\
\text { details of this activity are given in } \\
\text { Section 2. }\end{array}$ \\
\hline Abstract conceptualization & PowerPoint & $\begin{array}{l}\text { As described in Section 3, a } \\
\text { PowerPoint presentation was given } \\
\text { for students so that they could connect } \\
\text { what they learned to theory }\end{array}$ \\
\hline Concrete experience & Remote laboratory & $\begin{array}{l}\text { They could remotely connect to the } \\
\text { laboratory setup and carry out a } \\
\text { simple power factor correction } \\
\text { experiment. It is described in Section } \\
\text { activity }\end{array}$ \\
& & $\begin{array}{l}\text { It is designed to reflect on observation } \\
\text { and connect it to the field. It is } \\
\text { described in Section 5. }\end{array}$ \\
\hline Reflective observation \& & Final report &
\end{tabular}

\section{Pre-lab Work}

It contains several short tasks that help students connect their activities to the real world. The tasks were based on a single-phase pump load connected to a 230 V R.M.S. supply. In order to personalize the activity, the pump's capacity was tied with the student's registration number. As a result, the pump's capacity is $7.5 \mathrm{Z} \mathrm{kW}$ (where $\mathrm{Z}$ is the reminder of the [Registration number/3] plus 1 ), and the operating power factor at $100 \%$ loading is at 0.87 . The tasks are given in Table 2 . 
Table 2. Tasks are given in the pre-lab work

\begin{tabular}{cl}
\hline Task & \multicolumn{1}{c}{ Description } \\
\hline 1 & Represent the load by a resistor (R) in series with an inductor (L) \\
\hline 2 & $\begin{array}{l}\text { The pump is connected to a distribution board } 20 \mathrm{~m} \text { apart. Select a suitable cable to } \\
\text { supply the pump (cable data was given) }\end{array}$ \\
\hline 3 & \begin{tabular}{l} 
Calculate the capacitance required to improve the power factor to 0.99 \\
\hline 4
\end{tabular} \\
$\begin{array}{l}\text { Compare the power loss and voltage drop across the cable without and with the } \\
\text { capacitor }\end{array}$ \\
\hline
\end{tabular}

\section{Simulation and Reflections}

This simulation exercise is based on the 'Circuit Simulator Applet' available at https://falstad.com/circuit/. The reason for using this Applet is easy accessibility. In the usual classroom, P.S.C.A.D. is used. The installation of this software will need special support, and also, data charges to download the software are not affordable to some students. This simulation is based on the pre-lab work that they did. An instruction sheet was given to use the Circuit Simulator Applet. The tasks are given in Table 3.

\section{Table 3. Tasks for the simulations and reflections}

\begin{tabular}{cl}
\hline Task & \multicolumn{1}{c}{ Description } \\
\hline 1 & $\begin{array}{l}\text { Implement the R-L representation of the pump load considered in the prelab in 'Circuit } \\
\text { Simulator Applet.' }\end{array}$ \\
\hline 2 & $\begin{array}{l}\text { Using the scopes available in the Applet, obtain the waveforms of load current, load } \\
\text { voltage, and power consumed by the resistive part of the load and inductive part of the } \\
\text { load. }\end{array}$ \\
\hline 3 & $\begin{array}{l}\text { Using the waveform obtained, calculate the power factor of operation and compare it } \\
\text { with the calculated value. }\end{array}$ \\
\hline 5 & $\begin{array}{l}\text { Implement the above load with the power factor correction capacitor in the 'Circuit } \\
\text { Simulator Applet' and obtain the load voltage and current. }\end{array}$ \\
\hline 5 & $\begin{array}{l}\text { Obtain using the Applet the losses in the cable when the pump is operating at 100\% } \\
\text { loading without and with the power factor correction capacitor and compare the results } \\
\text { with the calculated value }\end{array}$ \\
\hline 6 & $\begin{array}{l}\text { Reflect on the calculated and simulated results for any discrepancies and write down } \\
\text { reasons for such discrepancies. }\end{array}$ \\
\hline
\end{tabular}

\section{PowerPoint presentation}

This presentation carried different types of real loads and their R-L representation, consequences of low power factor operation, power factor measurement techniques, and power factor correction. Some slides are shown in Figure 2.
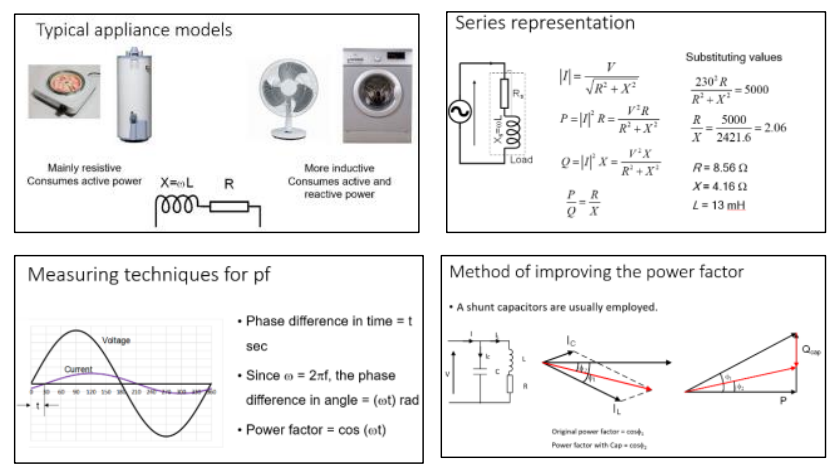

Figure 2. Some slides provided for abstract conceptualization

IJAE Page 5 


\section{Online laboratory activity}

This section provides a comprehensive commentary on the development of the laboratory setup. Figure 3 provides the overall setup developed. The power factor improvement circuit consists of a resistor, inductor, capacitor, relay switch, and a variac. The sensor circuit consists of a current sensor, voltage sensor, an op-amp circuit to obtain power factor, and Arduino U.N.O. controlling board. Raspberry pi and the oscilloscope were exposed to the internet using two real I.P.s such that they can be accessed through the internet from any network.

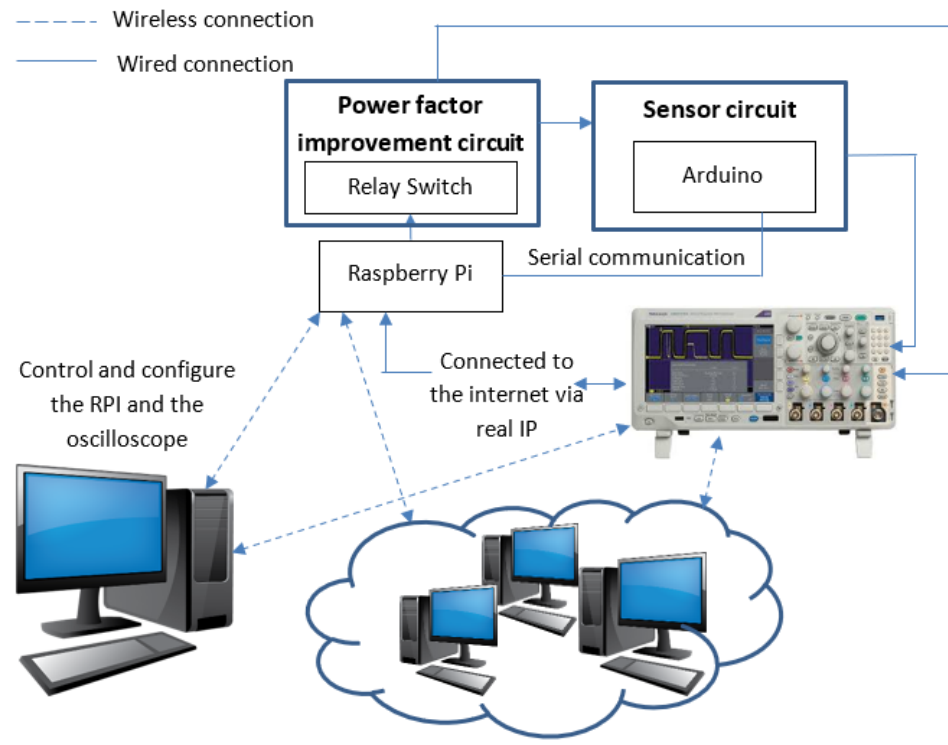

Figure 3. Components of the online laboratory setup

\subsection{Power factor improvement circuit}

Figure 4 shows the hardware setup used in the power factor correction experiment. The relay switch connects or disconnects the capacitor to the R.L. load. The relay signal is given via a raspberry pi digital output port. The relay ON and OFF commands were given to a remote user via a web application to the raspberry pi.

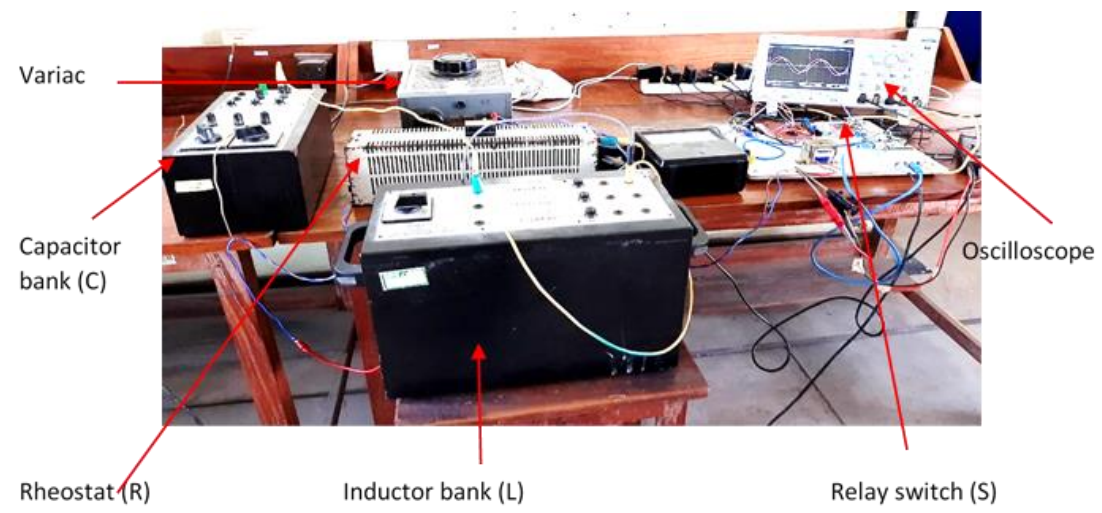

Figure 4. Hardware setup

\subsection{Sensor circuit to obtain voltage, current, and power factor measurements}

Figure 5 shows a diagram of the sensor circuit. It consists of current and voltage sensing devices, op-amp I.C.s, an XOR gate I.C. and Arduino-UNO microcontroller board. The voltage and current sensing devices were used to measure the voltage and current of the circuit. The op-amp comparator circuit was used with an XOR gate to obtain the power factor. The sensing signals were sent to the analog input pins 
in the Arduino board, and the pulse generated by the XOR gate I.C. was also set to a digital input pin of the Arduino board. Finally, the mathematical calculations were bone inside the Arduino board to obtain root mean squared voltage, root mean squired current, and the power factor.

\subsection{Web-based Oscilloscope}

An oscilloscope was used with a current probe and remote voltage probes to observe the circuit current and waveforms. The oscilloscope, current probe, and voltage probes used were Tektronix MDO 3014, Tektronix A622, and GW-Instek GDP-025. The MDO 3014 oscilloscope was used, which can access through the internet. In addition, the URL of the oscilloscope was placed as a button in the G.U.I. to enable students to access it.

\subsection{The graphical user interface of the system}

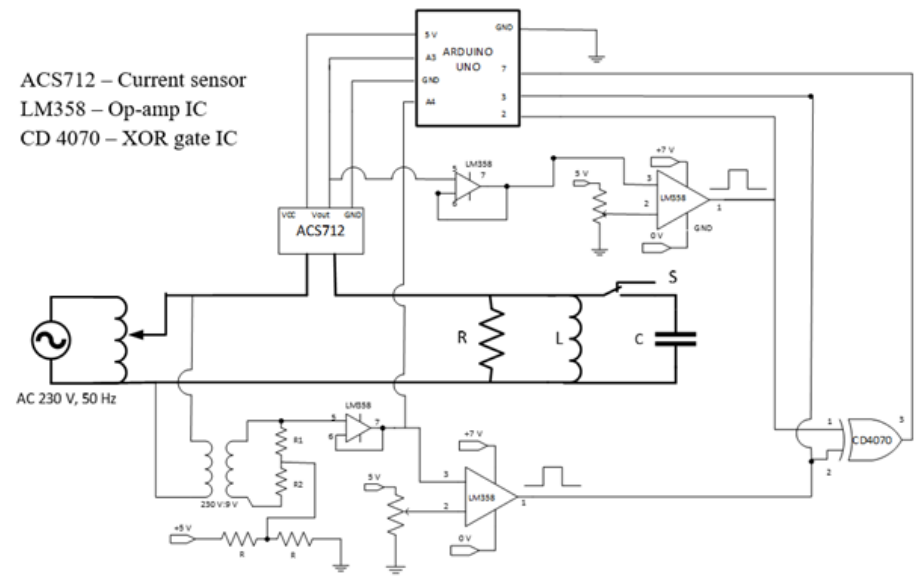

Figure 5. Sensing circuit

Figure 6 shows the lab setup's graphical user interface (G.U.I.). Again, HTML and CSS coding was used on the G.U.I. programming. The interface shows the R.L.C. circuit's voltage, current, and power factor measurements. Further, to operate the relay switch (to add or remove the capacitor from the R.L.C. circuit), a button was placed. The button toggles between 'add capacitor' and 'remove the capacitor.'

Furthermore, a link was added to access the oscilloscope. To explore a different aspect of the experiment individually, an instruction sheet was developed while providing clear instructions. Each student was assigned a specific time to access the laboratory setup. It was to minimize any issues that may created due to high traffic. The tasks students were asked to carry out are summaries in Table 4.

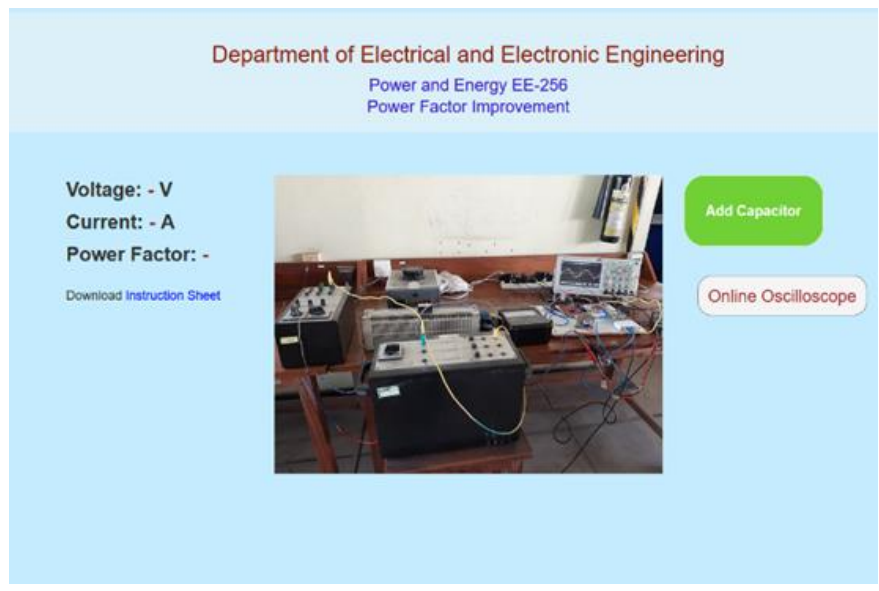

Figure 6. The graphical user interface of the lab setup

IJAE Page 7 
Table 4 Activities in the online lab

\begin{tabular}{cl} 
Task & \multicolumn{1}{c}{ Activity } \\
\hline $\mathbf{1}$ & $\begin{array}{l}\text { When the toggle switch is at the 'add capacitor' position, obtain the voltage, current, and } \\
\text { power factor measurements. }\end{array}$ \\
\hline $\mathbf{2}$ & $\begin{array}{l}\text { Go to the oscilloscope window and observe the waveform patterns. Also, using the } \\
\text { oscilloscope settings, calculate the power factor. }\end{array}$ \\
\hline $\mathbf{3}$ & Go back to the initial window \\
\hline $\mathbf{4}$ & Click on the "Add Capacitor" to switch the power factor correction capacitor \\
\hline $\mathbf{6}$ & Obtain the voltage, current, and power factor readings \\
\hline
\end{tabular}

\section{Final report}

The final report is a formal report where students are asked to report each activity's results under Sections 1 to 4. Students are then asked to discuss discrepancies of different results and reasons for them. It is anticipated that this report will be a take-home guide to apply their knowledge to wide applications when they graduate as Engineers.

\section{RESULTS AND DISCUSSION}

\section{Student Performance and Reflections}

Figure 7 shows the marks distribution of students who experimented on power factor correction from 2017 to 2021. From 2017 to 2019, the experiment was done in the laboratory. Students submitted a pre-lab report as described in Table 1 before experimenting and then submitted the final report. The main difference between how the experiment was conducted prior to the COVID period and after 2020 was no simulation activity, a 2-hour laboratory experiment, and experimenting with groups of 3 students. In 2020, students individually did the first three steps in Table 1, i.e., pre-lab work, simulations and reflections, and PowerPoint presentation. The remote laboratory setup was not available that year. This paper describes the steps followed in 2021. The main difference noted when the student experimented with groups and individuals is some outliers in 2020 and 2021. More importantly, on average, students' performance was improved when adopting the methodology described in this paper.

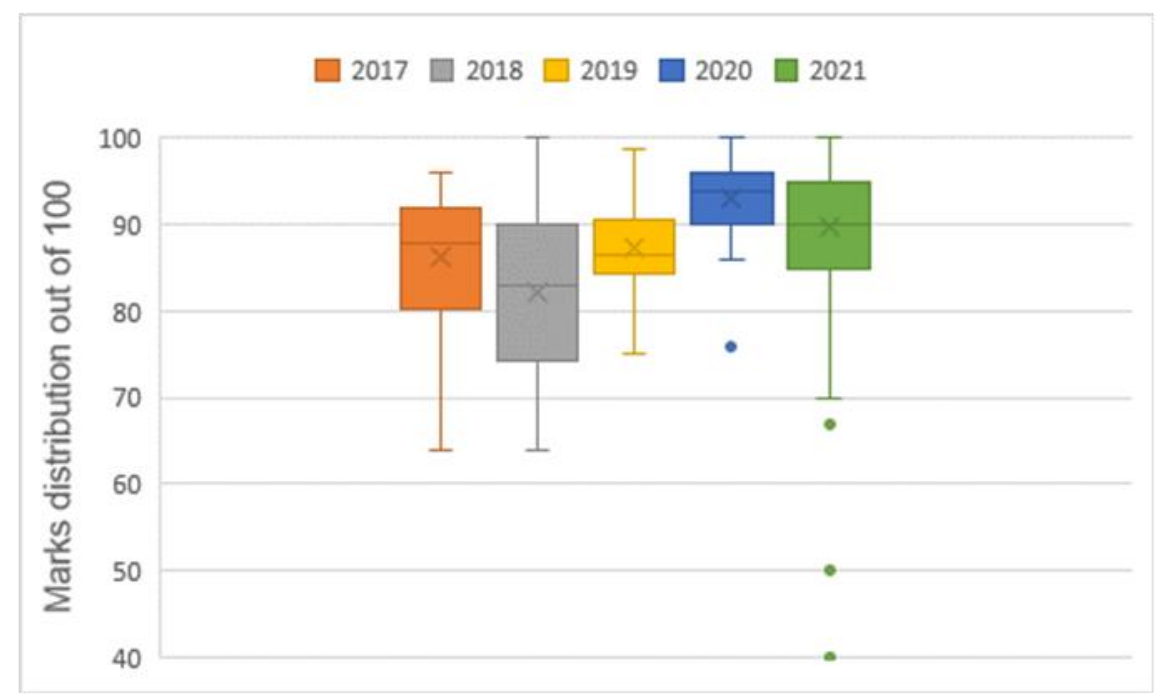

Figure 7. The marks distribution of students who experimented on power factor correction from 2017 to 2021 
In order to assess whether students fulfill the intended learning outcomes, a google form was developed that provided some close-ended and open-ended questions. Table 5 summaries the responses to some of the close-ended questions:

Table 5 Questions and Student's responses

\begin{tabular}{lccc}
\hline \multicolumn{1}{c}{ Question } & $\begin{array}{c}\text { Strongly } \\
\text { Agree on \% }\end{array}$ & Agree on \% & Other \% \\
\hline $\begin{array}{l}\text { Narrated PowerPoint presentation provided a } \\
\text { good insight into the online experiment }\end{array}$ & 51.7 & 40 & 8.3 \\
\hline $\begin{array}{l}\text { The simulation was intellectually simulating } \\
\begin{array}{l}\text { Simulation and PowerPoint provided a good } \\
\text { base so that I could connect this experiment to } \\
\text { real world }\end{array}\end{array}$ & 16.7 & 46.7 & 36.6 \\
\hline $\begin{array}{l}\text { The instruction sheet provided for the online lab } \\
\text { was informative and useful }\end{array}$ & 42.4 & 33.9 & 42.4 \\
\hline $\begin{array}{l}\text { Allowing to visualize the oscilloscope trace was } \\
\text { useful }\end{array}$ & 20.0 & 46.8 & 33.8 \\
\hline
\end{tabular}

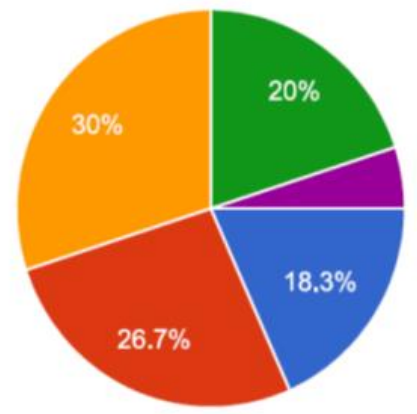

Figure 8. Student responses

For the close-ended question, 'under COVID-19 learning from home situation, the online lab backed by PowerPoint presentation and simulations was an ideal alternative,' the response is shown in Figure 8. Some of the responses to the open-ended questions are given in the following quotes:

"It is a good opportunity for us to complete our lab assignments online in this pandemic situation. But we are missing the hands-on experience, which is important".

"With the country's situation, this way of conducting lab sessions is very useful as we can come with a good idea about the lab session though we could not make our setup. Nevertheless, it gave me a good experience never had before. Allowing time slots to use the setup individually is good as everyone can engage in this lab session. Everything was well planned, and thank you for trying something new".

"The instruction sheet and the video before the lab are very understandable and sufficient for doing the lab."

"I think it is a very good idea to provide us with a virtual laboratory experience during this period as it can be considered as one of the best alternatives for physical labs. However, I believe that this can be improved greatly by adding more features such as the ability to change component values. In addition, we can assign login credentials (or something similar) to us so that only one student can 
access the lab during a given time slot. The key feature I saw in this virtual lab concept was that we see a realistic result, rather than a simulated result".

However, due to some technical hiccups, some students had issues. They responded as:

"Interface of the virtual lab is good if all functions were working. If all are working well, this approach is ideal to do our lab classes".

"When I was trying to do the lab, I could not access the lab in the time slot that was assigned to me. The setup was not working".

"The values of voltage, current, and power factor were correctly updated, and the "Add/Remove Capacitor" button worked. The only problem was that we could not access the oscilloscope screen due to a connection error. It would have been a really good experience if we were able to connect to it and obtain the necessary readings".

"There were some connection issues at the beginning. But later on, everything was fine and successfully finished".

\section{CONCLUSION}

It was recognized by many Engineering educators that processes associated with some modules could not be delivered effectively through the online environment. The online mode for laboratory experiments during the COVID-19 Pandemic was new to many educators, and they often had doubts about the planning and delivery of laboratory experiments. Considering these facts, this paper presented a theoretical framework based on experiential learning to plan and deliver experiments online. Since a laboratory session online should be shorter, the proposed theoretical framework is ideally suited to deliver laboratory sessions in several shorter activities. A case study based on the power factor correction was used to demonstrate the planning and execution of the proposed delivery model. Students' performance was compared before and after the online mode of delivery, and it was found that students' performance was improved when the laboratory activity was conducted as described in this paper. Students' opinion about this mode was obtained using an online questionnaire. In general, students like the idea of a remote lab and how it was delivered. A few issues with the laboratory setup were also highlighted. It was recognized that a better way of accessing the oscilloscope is important, and latency should be improved.

\section{Funding and Conflicts of Interest}

The author declares no funding and conflicts of interest for this research.

\section{REFERENCES}

Adedoyin, O. B., \& Soykan, E. (2020). Covid-19 Pandemic and online learning: The challenges and opportunities. Interactive Learning Environments, $0(0), 1-13$. https://doi.org/10.1080/10494820.2020.1813180

Almeida, A. M. d, Fernandes, J., Pascoal, M., \& Pereira, S. (2009). Experiential Learning in Science: Getting the Laboratory Inside the Classroom Using the Web. 2009 Ninth IEEE International Conference on Advanced Learning Technologies, 327-328. https://doi.org/10.1109/ICALT.2009.173

Balamuralithara, B., \& Woods, P. C. (2009). Virtual laboratories in engineering education: The simulation lab and remote lab. Computer Applications in Engineering Education, 17(1), 108118. https://doi.org/10.1002/cae.20186

Basilaia, G., \& Kvavadze, D. (2020). Transition to Online Education in Schools during a SARS-CoV-2 Coronavirus (COVID-19) Pandemic in Georgia. Pedagogical Research, 5(4). 
Bourne, J., Harris, D., \& Mayadas, F. (2005). Online Engineering Education: Learning Anywhere, Anytime. Journal of Engineering Education, 94(1), 131-146. https://doi.org/10.1002/j.21689830.2005.tb00834.x

Chai, H., Priestley, M., Tang, X., \& Ravishankar, J. (2020). Implementation of Microgrid Virtual Laboratory in a Design Course in Electrical Engineering. 2020 IEEE International Conference on Teaching, Assessment, and Learning for Engineering (TALE), 509-515. https://doi.org/10.1109/TALE48869.2020.9368350

Collins, J. T., Knapper, J., Stirling, J., McDermott, S., \& Bowman, R. (2021). Modern Microscopy with the Web of Things: The OpenFlexure Microscope Software Stack. ArXiv:2101.00933 [Physics]. http://arxiv.org/abs/2101.00933

Das, S. (2018). Design and Implementation of MATLAB-Simulink Based Solar Cell Modeling and P.V. System Design Exercises for Advanced Student Learning. 2018 A.S.E.E. Annual Conference \& Exposition Proceedings, 30263. https://doi.org/10.18260/1-2--30263

Ertugrul, N. (n.d.). New Era in Engineering Experiments: An Integrated and Interactive Teaching/Learning Approach, and Real-Time Visualisations. 13.

Feisel, L. D., \& Rosa, A. J. (2005). The Role of the Laboratory in Undergraduate Engineering Education. Journal of Engineering Education, 94(1), 121-130. https://doi.org/10.1002/j.21689830.2005.tb00833.x

Feisel, L., Peterson, G. D., \& Emeritus, D. (2002). A Colloquy on Learning Objectives For Engineering Education Laboratories. https://doi.org/10.18260/1-2--11246

Ferreira, J. M. M., Costa, R. J., Alves, G. R., \& Cooper, M. (2002). THE PEARL DIGITAL ELECTRONICS LAB: FULL ACCESS TO THE WORKBENCH VIA THE WEB. 6.

Goldberg, H. R., \& Dintzis, R. (2007). The positive impact of team-based virtual microscopy on student learning in physiology and histology. Advances in Physiology Education, 31(3), 261-265. https://doi.org/10.1152/advan.00125.2006

Gorghiu, G., \& Santi, E. A. (2016). Applications of Experiential Learning in Science Education Non-Formal Contexts. 320-326. https://doi.org/10.15405/epsbs.2016.11.33

Hasan, B., Al-Quorashy, Y., Al-Mousa, S., Al-Sahhaf, Y., \& El-Abd, M. (2020). V-LAB - The Virtual Electric Machines Laboratory. 2020 IEEE Global Engineering Education Conference (E.D.U.C.O.N.), 72-77. https://doi.org/10.1109/EDUCON45650.2020.9125349

Kolb, D. A. (1984). Experiential learning: Experience as the source of learning and development. Prentice-Hall.

Ma, J., \& Nickerson, J. V. (2006). Hands-on, simulated, and remote laboratories: A comparative literature review. A.C.M. Computing Surveys, 38(3), 7-es.

https://doi.org/10.1145/1132960.1132961

Morris, T. H. (2020). Experiential learning - a systematic review and revision of Kolb's model. Interactive Learning Environments, 28(8), 1064-1077. https://doi.org/10.1080/10494820.2019.1570279

Mosterman, P. J., Campbell, J. O., Brodersen, A. J., \& Bourne, J. R. (1996). Design and implementation of an electronics laboratory simulator. IEEE Transactions on Education, 39(3), 309-313. https://doi.org/10.1109/13.538752

Odeh, S., Shanab, S. A., Anabtawi, M., \& Hodrob, R. (2013). A Remote Engineering Lab based on Augmented Reality for Teaching Electronics. International Journal of Online and Biomedical Engineering (I.J.O.E.), 9(S5), 61-67. 
Osipov, I. V., Prasikova, A. Y., \& Volinsky, A. A. (2015). Participant behavior and content of the online foreign languages learning and teaching platform. Computers in Human Behavior, 50, 476-488. https://doi.org/10.1016/j.chb.2015.04.028

Peterson, G. D., \& Feisel, L. D. (n.d.). e-Learning: The Challenge for Engineering Education. 6.

Solak, S., Yakut, Ö., \& Dogru Bolat, E. (2020). Design and Implementation of Web-Based Virtual Mobile Robot Laboratory for Engineering Education. Symmetry, 12(6), 906. https://doi.org/10.3390/sym12060906

Tang, T., Abuhmaid, A. M., Olaimat, M., Oudat, D. M., Aldhaeebi, M., \& Bamanger, E. (2020). Efficiency of flipped classroom with online-based teaching under COVID-19. Interactive Learning Environments, O(0), 1-12. https://doi.org/10.1080/10494820.2020.1817761

Valdez, M. T., Ferreira, C. M., Martins, M. J. M., \& Barbosa, F. P. M. (2014). Virtual labs in electrical engineering education-The V.E.M.A. environment. 2014 Information Technology Based Higher Education and Training (I.T.H.E.T.), 1-5. https://doi.org/10.1109/ITHET.2014.7155714 